This is an electronic reprint of the original article. This reprint may differ from the original in pagination and typographic detail.

Author(s): Chivers, Tristram; Ritch, Jamie; Robertson, Stuart; Konu, Jari; Tuononen, Heikki

Title: $\quad$ New Insights into the Chemistry of Imidodiphosphinates from Investigations of Tellurium-Centered Systems

Year: $\quad 2010$

Version:

Please cite the original version:

Chivers, T., Ritch, J., Robertson, S., Konu, J., \& Tuononen, H. (2010). New Insights into the Chemistry of Imidodiphosphinates from Investigations of Tellurium-Centered Systems. Accounts of Chemical Research, 43(8), 1053-1062.

https://doi.org/10.1021/ar900272k

All material supplied via JYX is protected by copyright and other intellectual property rights, and duplication or sale of all or part of any of the repository collections is not permitted, except that material may be duplicated by you for your research use or educational purposes in electronic or print form. You must obtain permission for any other use. Electronic or print copies may not be offered, whether for sale or otherwise to anyone who is not an authorised user. 


\title{
New Insights into the Chemistry of Imidodiphosphinates from Investigations of Tellurium-Centered Systems
}

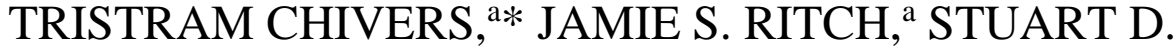 \\ ROBERTSON, ${ }^{\mathrm{a}, \mathrm{c}}$ JARI KONU ${ }^{\mathrm{a}}$ and HEIKKI M. TUONONEN ${ }^{\mathrm{b}}$
}

a. Department of Chemistry, University of Calgary, 2500 University Drive NW, Calgary, AB, T2N 1N4, Canada

b. Department of Chemistry, University of Jyväskylä, Jyväskylä, FI-40014, Finland

c. Current address: Department of Chemistry, University of Strathclyde, Glasgow, Scotland G1 $1 X Q$

E-mail: chivers@ucalgary.ca; Fax: (+1)403-289-9488; Tel: (+1)403-220-5741 


\section{CONSPECTUS}

Dichalcogenido-imidodiphosphinates $\left[\mathrm{N}\left(\mathrm{PR}_{2} \mathrm{E}\right)_{2}\right]^{-}(\mathrm{R}=$ alkyl, aryl $)$ are chelating ligands that readily form cyclic complexes with main group or transition metals, as well as lanthanides and actinides. Since their discovery in the early 1960s, the structural chemistry of these metal complexes for $\mathrm{E}=\mathrm{O}, \mathrm{S}$, Se has been studied extensively and a variety of potential applications have been identified, for example, as NMR shift reagents, luminescent complexes in photonic devices, or single-source precursors for metal sulfides or selenides. A suitable synthesis of the tellurium analogs $\left[\mathrm{N}\left(\mathrm{PR}_{2} \mathrm{Te}\right)_{2}\right]^{-}$ was not developed until 2002. In the intervening 7 years comprehensive investigations of these tellurium-centered anions, as well as related mixed chalcogen systems, have revealed unanticipated aspects of the fundamental chemistry of these well-established inorganic ligands. An exhaustive examination of previously unrecognized redox behavior has uncovered a variety of novel dimeric arrangements, as well as an extensive series of cyclic cations. In combination with DFT calculations, these new structural frameworks have provided new insights into the nature of chalcogen-chalcogen bonding. Unprecedented structural and reaction chemistry has also been revealed in studies of metal complexes of the ditellurido ligands $\left[\mathrm{N}\left(\mathrm{PR}_{2} \mathrm{Te}\right)_{2}\right]^{-}$. The large tellurium donor sites confer greater flexibility leading, in some cases, to unique structures in which the tellurium-centered ligand bridges two metal centers. The relatively weak $\mathrm{P}-\mathrm{Te}$ bonds facilitate metal-insertion reactions (intramolecular oxidative-addition) to give new metaltellurium ring systems for some group 11 and 13 metals. From a practical perspective, certain metal complexes of the isopropyl-substituted anion $\left[\mathrm{N}\left(\mathrm{P}^{\mathrm{i}} \mathrm{Pr}_{2} \mathrm{Te}\right)_{2}\right]^{-}$serve as suitable single-source precursors for pure metal telluride thin films or novel 
nanomaterials, e.g. $\mathrm{CdTe}, \mathrm{PbTe}, \mathrm{In}_{2} \mathrm{Te}_{3}, \mathrm{Sb}_{2} \mathrm{Te}_{3}$, which have potential applications in solar cells, thermoelectric devices and telecommunications.

\section{Introduction}

Chalcogen-centered chelating ligands of the type $\left[\mathrm{N}\left(\mathrm{PR}_{2} \mathrm{E}\right)_{2}\right]^{-}(\mathrm{E}=\mathrm{O}, \mathrm{S}, \mathrm{Se} ; \mathrm{R}=$ alkyl, aryl) [i.e. dichalcogenido(imidodiphosphinates) (PNP)] have a long and venerable history that dates back to the $1960 \mathrm{~s}^{1}$ In the intervening years many main group and transitionmetal complexes have been characterized. ${ }^{2}$ Some early potential applications of these complexes included their use as lanthanide shift reagents, in luminescent materials, or in metal-extraction processes. ${ }^{2 a}$ More recently, renewed interest in this class of compounds has been invigorated by the findings of O'Brien and co-workers that certain metal complexes of the isopropyl derivative $\left[\mathrm{N}\left(\mathrm{P}^{\mathrm{i}} \mathrm{Pr}_{2} \mathrm{Se}\right)_{2}\right]^{-}$are suitable single-source precursors for the production of thin semiconducting films of binary metal selenides, e.g. MSe $(\mathrm{M}=$ $\mathrm{Zn}, \mathrm{Cd}, \mathrm{Hg}), \mathrm{M}_{2} \mathrm{Se}_{3}(\mathrm{M}=\mathrm{Ga}, \mathrm{In}, \mathrm{Bi})$ and $\mathrm{PbSe}$, by using LP-(low-pressure) or AA(aerosol-assisted) CVD (chemical vapor deposition) techniques. ${ }^{3}$ The solvothermal generation of CdSe quantum dots has also been accomplished. ${ }^{4}$ In addition to the synthetic challenge of making analogous Te-containing ligands that might display novel chemistry, the prospect of generating novel single-source precursors to metal tellurides excited our interest in this field.

\section{Synthesis}

The neutral precursors $\mathrm{HN}\left(\mathrm{PR}_{2} \mathrm{E}\right)_{2}\left(\mathrm{E}=\mathrm{S}, \mathrm{Se} ; \mathrm{R}=\mathrm{Ph},{ }^{\mathrm{i}} \mathrm{Pr}\right)$ are readily generated by the direct reaction of the corresponding $\mathrm{P}^{\mathrm{III}} / \mathrm{P}^{\mathrm{III}}$ systems $\mathrm{HN}\left(\mathrm{PR}_{2}\right)_{2}$ with elemental sulfur or 
selenium. ${ }^{5}$ In the case of tellurium, however, this oxidation is limited to the formation of the yellow monotellurido derivative $\operatorname{Te}^{\mathrm{i}} \mathrm{Pr}_{2} \mathrm{PNP}(\mathrm{H}){ }^{\mathrm{i}} \mathrm{Pr}_{2}(\mathbf{1 a}){ }^{6}$ which is isolated as the $\mathrm{P}-\mathrm{H}$ tautomer in $81 \%$ yield (Scheme 1); the phenyl derivative $\mathrm{HN}\left(\mathrm{PPh}_{2}\right)_{2}$ is unreactive towards tellurium. ${ }^{7}$ In 2002 we demonstrated that this lack of reactivity can be circumvented by generating the anion $\left[\mathrm{N}\left(\mathrm{PPh}_{2}\right)_{2}\right]^{-}$prior to the reaction with elemental tellurium. In this way sodium salts of the ditellurido ligands $\left[\mathrm{N}\left(\mathrm{PR}_{2} \mathrm{Te}\right)_{2}\right]^{-}\left(\mathbf{2 a}, \mathrm{R}={ }^{\mathrm{i}} \mathrm{Pr} ;{ }^{8}\right.$ $\mathbf{2} \mathbf{a}^{\prime}, \mathrm{R}=\mathrm{Ph} ;{ }^{7} \mathbf{2} \mathbf{a}^{\prime \prime}, \mathrm{R}={ }^{\mathrm{t}} \mathrm{Bu}^{9}$ ) are obtained in good yields (Scheme 1). This protocol can be adapted for the synthesis of the mixed chalcogen ligands $\left[\mathrm{N}\left(\mathrm{P}^{\mathrm{i}} \operatorname{Pr}_{2} \mathrm{Te}\right)\left(\mathrm{P}^{\mathrm{i}} \mathrm{Pr}_{2} \mathrm{E}\right)\right]^{-}(\mathrm{E}=\mathrm{S}$, Se) (Scheme 1). ${ }^{10}$ The best procedure for obtaining the Te/S ligand, as the Li derivative 2c, in high purity (99\%) involves the in situ deprotonation of the monotelluride (1a) with $n$-butyllithium followed by reaction with sulfur in THF. A similar methodology is employed for the optimal synthesis of the Te/Se reagent $\mathbf{2 b}$ ( $97 \%$ purity) from the monoselenide (1b). The mixed chalcogen anions $\left[\mathrm{N}\left(\mathrm{P}^{\mathrm{i}} \mathrm{Pr}_{2} \mathrm{Te}\right)\left(\mathrm{P}^{\mathrm{i}} \mathrm{Pr}_{2} \mathrm{E}\right)\right]^{-}(\mathrm{E}=\mathrm{S}, \mathrm{Se})$ can also be obtained as ion-separated cobaltocenium salts by reduction of the corresponding cations (see Section 3.2) with cobaltocene. ${ }^{11}$ The "metallation-first" approach to these novel tellurium-containing ligands opened the door to a comprehensive investigation of their fundamental chemistry, as well as potential applications of metal complexes as single-source precursors to metal tellurides in the form of thin films or nanomaterials.

\section{Redox Behavior}

3.1. One-electron Oxidation. In our initial studies we observed that yellow solutions of the monotelluride 1a become red upon exposure to air and a few crystals of the unusual ditelluride ( $\left.\mathrm{TeP}^{\mathrm{i}} \mathrm{Pr}_{2} \mathrm{~N}^{\mathrm{i}} \mathrm{Pr}_{2} \mathrm{PTe}-\right)_{2}$ (4a) were isolated from the red solution and structurally 
characterized. ${ }^{6}$ This intriguing transformation prompted us to undertake a systematic examination of the redox behavior of the monoanions $\left[\mathrm{N}\left(\mathrm{PR}_{2} \mathrm{E}\right)_{2}\right]^{-}(\mathrm{E}=\mathrm{S}, \mathrm{Se}, \mathrm{Te} ; \mathrm{R}=$ $\left.{ }^{i} \mathrm{Pr},{ }^{\mathrm{t}} \mathrm{Bu}\right)$. The one-electron oxidation of their sodium salts with iodine produces the dimers $\left(\mathrm{EPR}_{2} \mathrm{NR}_{2} \mathrm{PE}-\right)_{2}$ either in the form of dichalcogenides (DCs) $\mathbf{4 a}, \mathbf{4} \mathbf{b}, \mathbf{4} \mathbf{b}^{\prime}$ and $\mathbf{4} \mathbf{c}^{\prime}$ or as the spirocyclic contact ion pair (CIP) $5 \mathbf{a}^{\prime} \cdot{ }^{9}$ The disulfide $\mathbf{4 c}\left(\mathrm{E}=\mathrm{E}^{\prime}=\mathrm{S} ; \mathrm{R}={ }^{\mathrm{i}} \operatorname{Pr}\right)$ could not be obtained owing to hydrogen-abstraction reactions. ${ }^{9}$ The availability of the mixed chalcogen anions in $\mathbf{2 b}$ and $2 \mathbf{c}$ provoked the interesting question - which chalcogen-chalcogen bond will be formed preferentially upon one-electron oxidation, EE, Te-Te or E-Te? Although the oxidation of $\mathbf{2 b}$ and $\mathbf{2} \mathbf{c}$ with $\mathrm{I}_{2}$ does not proceed cleanly, one-electron reduction of the corresponding cations $\left[\mathrm{N}\left(\mathrm{P}^{\mathrm{i}} \mathrm{Pr}_{2} \mathrm{Te}\right)\left(\mathrm{P}^{\mathrm{i}} \mathrm{Pr}_{2} \mathrm{E}\right)\right]^{+}(\boldsymbol{6} \boldsymbol{c}, \mathrm{E}=\mathrm{Se}$; 6d, $\mathrm{E}=\mathrm{S}$ ) with cobaltocene produces the ditellurides $\mathbf{4 d}$ and $\mathbf{4 e}$; in both cases the dimer with a central Te-Te bond is formed exclusively. ${ }^{11}$

The structures of the DCs $\mathbf{4 a}, \mathbf{4 b}, \mathbf{4} \mathbf{b}^{\prime}, \mathbf{4} \mathbf{c}^{\prime}, \mathbf{4 d}$ and $\mathbf{4 e}$ all exhibit elongated chalcogen-chalcogen bonds. ${ }^{9,11}$ The elongation of the central Te-Te bond in the mixed chalcogen dimers $4 \mathbf{d}$ (ca. $6 \%$ ) and $4 \mathbf{e}($ ca. $3 \%$ ) is less pronounced than the value of ca. 8 $\%$ for the all-tellurium system 4a. DFT calculations for the radical $\left[\mathrm{TeP}^{\mathrm{i}} \mathrm{Pr}_{2} \mathrm{~N}^{i} \mathrm{Pr}_{2} \mathrm{PTe}\right]^{*}$ reveal that the SOMO is comprised of an almost linear combination of tellurium $\mathrm{p}_{\mathrm{x}}$ and $\mathrm{p}_{\mathrm{y}}$ orbitals (Figure 1). The spatial orientation of monomeric units in the dimer and the multicentered nature of the radical SOMO effectively weaken the Te-Te bonding interaction thus accounting for the elongated $\mathrm{Te}-\mathrm{Te}$ bond. Consistently, the calculated dimerization energy for the model reaction $2\left[\mathrm{TePMe}_{2} \mathrm{NMe}_{2} \mathrm{PTe}\right]^{*} \rightarrow\left(\mathrm{TePMe}_{2} \mathrm{NMe}_{2} \mathrm{PTe}-\right.$ )$_{2}$ is $-80 \mathrm{~kJ} \mathrm{~mol}^{-1},{ }^{6} \mathrm{cf} . \mathrm{D}(\mathrm{Te}-\mathrm{Te})=138 \mathrm{~kJ} \mathrm{~mol}^{-1}$ for $\mathrm{PhTe}-\mathrm{TePh}$. The attenuation of the Te-Te bond elongation in the mixed chalcogen systems $\mathbf{4 d}$ and $\mathbf{4 e}$ compared to that in $\mathbf{4 a}$ 
is attributed to the polarization of the SOMO of the neutral radicals $\left[\mathrm{EP}^{\mathrm{i}} \mathrm{Pr}_{2} \mathrm{~N}^{i} \mathrm{Pr}_{2} \mathrm{PTe}\right]^{\circ}$ towards the more electropositive tellurium atom when $\mathrm{E}=\mathrm{S}$, Se resulting in stronger $\mathrm{Te}-$ Te overlap. ${ }^{11}$ The elongation of the central chalcogen-chalcogen bond in the diselenides $\mathbf{4 b}$ and $\mathbf{4} \mathbf{b}^{\prime}$ is ca. $6 \%$ and that in the disulfide $\mathbf{4} \mathbf{c}^{\prime}$ is only $2 \%$, suggesting better overlap of the two radical SOMOs for the lighter chalcogens We note, however, that the markedly different conformations of acyclic DCs is likely to be a contributing factor. ${ }^{9}$

DFT calculations of the relative energies of the two structural isomers observed for the symmetrical dimers $\left(\mathrm{EPR}_{2} \mathrm{NR}_{2} \mathrm{PE}-\right)_{2}$ (DC and CIP) as a function of (a) the chalcogen and (b) the R group reveal interesting trends. ${ }^{9}$ For both the ${ }^{\mathrm{i}} \mathrm{Pr}$ and ${ }^{\mathrm{t}} \mathrm{Bu}$ series the stability of the CIP increases relative to that of the DC upon going from sulfur to tellurium. However, the CIP is predicted to be significantly more stable in only one case $\left(\mathrm{R}={ }^{\mathrm{t}} \mathrm{Bu}, \mathrm{E}=\mathrm{Te}\right)$, consistent with the observed isolation of $\mathbf{5 a}$ '. However, the differences in energy are insignificant in the cases of $\mathrm{E}=\mathrm{Te}, \mathrm{R}={ }^{\mathrm{i}} \mathrm{Pr}$ and $\mathrm{E}=$ Se and $\mathrm{R}={ }^{\mathrm{t}} \mathrm{Bu}$. Thus, the preferred structure could be influenced by either (a) the method of synthesis or (b) crystal packing forces.

In this context we were intrigued to prepare and determine the structures of dimers in which the two monomeric units are different, e.g. $\left(\mathrm{EPR}_{2} \mathrm{NR}_{2} \mathrm{PE}-\right.$ $\left.\mathrm{TePR}_{2} \mathrm{NR}_{2} \mathrm{PTe}\right)(\mathrm{E}=\mathrm{Se}, \mathrm{S})$. The reactions of sodium salts of the acyclic anions $\left[(\mathrm{TMEDA}) \mathrm{NaN}\left(\mathrm{PR}{ }_{2} \mathrm{E}\right)_{2}\right]\left(\mathrm{E}=\mathrm{S}, \mathrm{Se} ; \mathrm{R}={ }^{\mathrm{i}} \mathrm{Pr},{ }^{\mathrm{t}} \mathrm{Bu}\right)$ with the cyclic cations $\left[\mathrm{N}\left(\mathrm{PR}_{2} \mathrm{Te}\right)_{2}\right]^{+} \mathrm{I}^{-}$ $\left(\mathrm{R}={ }^{\mathrm{i}} \mathrm{Pr},{ }^{\mathrm{t}} \mathrm{Bu}\right)$ (vide infra) proved to be an excellent route to such dimeric systems. ${ }^{12}$ Surprisingly, this protocol led to two different CIP structures depending on the nature of the R groups attached to phosphorus. Tert-butyl substituents give rise to the spirocyclic CIPs $\mathbf{5} \mathbf{b}^{\prime}$ and $\mathbf{5} \mathbf{c}^{\prime}$, whereas the corresponding iso-propyl derivatives $\mathbf{5 b}$ and $\mathbf{5 c}$ adopt a 
new CIP framework in which the five-membered acyclic anion $\left[\mathrm{N}\left(\mathrm{P}^{\mathrm{i}} \mathrm{Pr}_{2} \mathrm{E}\right)_{2}\right]^{-}(\mathrm{E}=\mathrm{S}, \mathrm{Se})$ is coordinated in an E-monodentate fashion to the cyclic cation $\left[\mathrm{N}\left(\mathrm{P}^{\mathrm{i}} \mathrm{Pr}_{2} \mathrm{Te}\right)_{2}\right]^{+} .^{12} \mathrm{DFT}$ calculations indicate that the observed bidentate coordination mode is more stable than the monodentate isomer by $35-45 \mathrm{~kJ} \mathrm{~mol}^{-1}$ for the tert-butyl derivatives $\mathbf{5 a} \mathbf{a}^{\prime} \mathbf{c}^{\prime}$, but preferred by only 5-10 $\mathrm{kJ} \mathrm{mol}^{-1}$ for the iso-propyl analogues $\mathbf{5 b}$ and $\mathbf{5 c}$; crystal packing forces may be responsible for the observed formation of monodentate arrangement in the latter case. $^{12}$

The trends in Te-Te bond lengths along the series 5a' (2.981 ̊́), 5b' (2.922 ̊́)

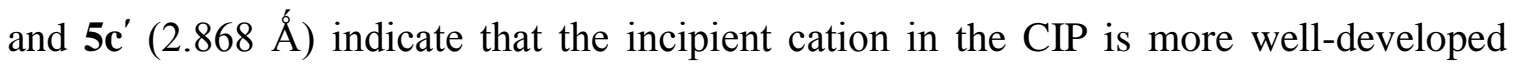
upon going from Te to $\mathrm{S}$ in the counter-anion. Comparison of the bond orders of the central chalcogen-chalcogen bonds reveals that this trend is determined by the strength of the anion-cation interaction. Thus, the Te-Te bond order increases as the E-Te bond order decreases. ${ }^{12}$ Consistently, DFT calculations predict that the extent of electron transfer is $0.20 \mathrm{e}^{-}$for $\mathbf{5} \mathbf{a}^{\prime}, 0.39 \mathrm{e}^{-}$for $\mathbf{5} \mathbf{b}^{\prime}$, and $0.50 \mathrm{e}^{-}$for $\mathbf{5} \mathbf{c}^{\prime}{ }^{12}$

3.2. Two-electron Oxidation. The facile formation of dimers upon one-electron oxidation of the monoanions $\left[\mathrm{N}\left(\mathrm{PR}_{2} \mathrm{E}\right)_{2}\right]^{-}\left(\mathrm{E}=\mathrm{S}\right.$, Se, Te; $\left.\mathrm{R}={ }^{\mathrm{i}} \mathrm{Pr},{ }^{\mathrm{t}} \mathrm{Bu}\right)$ evoked the possibility of generating the corresponding monocations via two-electron oxidation. Indeed, symmetrical cations of the type $\left[\mathrm{N}\left(\mathrm{P}^{\mathrm{i}} \mathrm{Pr}_{2} \mathrm{E}\right)_{2}\right]^{+}$are readily generated as the surprisingly air-stable iodide salts $\mathbf{6 a}$ and $\mathbf{6 b}$ by oxidation of the corresponding anions with one equivalent of $I_{2}$ (Scheme 2). ${ }^{13}$ The mixed chalcogen systems $\mathbf{6 c}$ and $\mathbf{6 d}$ are prepared in a similar manner. ${ }^{11}$ The hexafluoroantimonate salts $\mathbf{7 a}, \mathbf{b}$ are produced by metathesis of the corresponding iodide salts with $\mathrm{Ag}\left[\mathrm{SbF}_{6}\right]$ (Scheme 2). ${ }^{14}$ 
The salts $6 \mathbf{6}$ and $\mathbf{6} \mathbf{b}$ are comprised of a five-membered cyclic cation $\left[\mathrm{N}\left(\mathrm{P}^{\mathrm{i}} \mathrm{Pr}_{2} \mathrm{E}\right)_{2}\right]^{+}$ and an iodide counterion that interacts with one of the chalcogens to form an infinite chain structure (Figure 2). ${ }^{13}$ By contrast, the tert-butyl derivatives $\left[\mathrm{N}\left(\mathrm{P}^{\mathrm{t}} \mathrm{Bu}_{2} \mathrm{E}\right)_{2}\right] \mathrm{I}(\mathrm{E}=\mathrm{Se}$, $\mathrm{Te}$ ) are dimeric with close $\mathrm{Se}-\mathrm{Se}$ and $\mathrm{Te}-\mathrm{Te}$ contacts, while the sulfur system $\left[\mathrm{N}\left(\mathrm{P}^{\mathrm{t} B u} \mathrm{Su}_{2}\right)_{2}\right] \mathrm{I}_{3}$ is an ion-separated monomer with a triiodide counterion. ${ }^{9}$ In the mixed chalcogen systems $\mathbf{6 c}$ and $\mathbf{6 d}$ the iodide counterion interacts preferentially with the tellurium center. ${ }^{11}$ The Te-I interaction is much stronger with the mixed chalcogen cations ( $\mathbf{6 c}$ and $\mathbf{6 d})$ than that in the ditellurido cation (6a) to the extent that the former are essentially monomeric in the solid state.

Simple electron-counting rules predict that the cyclic cations $\left[\mathrm{N}\left(\mathrm{PR}_{2} \mathrm{E}\right)_{2}\right]^{+}$are $6 \pi-$ electron systems. DFT calculations confirm this prediction, but reveal that the net $\pi$-bond order within the five-membered ring is close to zero. The three highest occupied orbitals are indeed $\pi$-type orbitals (Figure 3 ). However, the bonding effect of the E-E $\pi$-bonding orbital (HOMO-2) is essentially cancelled by the double occupation of the HOMO, which is the $\mathrm{E}-\mathrm{E} \pi^{*}$-antibonding orbital. The third occupied $\pi$-orbital (HOMO-1) is a primarily non-bonding nitrogen-centered orbital.

The stronger iodide-chalcogen interaction in the mixed chalcogen salts $\mathbf{6 c}$ and $\mathbf{6 d}$ produces a more pronounced elongation of the chalcogen-chalcogen bonds in the cyclic cations $(\mathbf{6 c}, 8 \% \text {; } \mathbf{6 d}, 12 \%)^{11}$ than that observed for the Te-Te bond in $\mathbf{6 a}(4 \%) .{ }^{13 \mathrm{a}}$ The latter is attributed to the donation of electron density from a lone pair on the iodide counterion into the Te-Te $\sigma^{*}$ orbital (LUMO) (Figure 3) of the symmetrical cation in $\mathbf{6 a},{ }^{13 a, b} \mathrm{cf}$. the elongation of the I-I bond observed in the formation of the triiodide anion $\mathrm{I}_{3}{ }^{-}$from interaction of an $\mathrm{I}^{-}$anion and an I-I molecule. The $\sigma^{*}$ orbital (LUMO) in the 
mixed cations $\mathbf{6 c}$ and $\mathbf{6 d}$ is polarized towards tellurium (the more electropositive chalcogen) resulting in a stronger Te-I interaction and, concomitantly, a more pronounced lengthening of the E-Te bond. ${ }^{11}$

3.3 Solution NMR Studies. NMR spectra provide a wealth of information about the solution behavior of tellurium- and selenium-containing imidodiphosphinates as a result of the presence of spin-1/2 nuclei: ${ }^{31} \mathrm{P}(100 \%),{ }^{77} \mathrm{Se}(7.6 \%)$ and ${ }^{125} \mathrm{Te}(7.0 \%)$. The appearance of ${ }^{77} \mathrm{Se}$ and ${ }^{125} \mathrm{Te}$ satellites associated with ${ }^{31} \mathrm{P}$ resonances is a clear indicator of the P-E functionality, while the magnitude of the coupling constants ${ }^{1} J(\mathrm{PSe})$ and ${ }^{1} J(\mathrm{PTe})$ is inversely proportional to the P-E bond lengths and can be used to distinguish between terminal and bridging E atoms. ${ }^{14 a}$ Approximate ranges for ${ }^{1} J(\mathrm{PSe})$ and ${ }^{1} J(\mathrm{PTe})$ are $750-350$ and $1750-850 \mathrm{~Hz}$, respectively; terminal $\mathrm{P}=\mathrm{E}$ bonds are identified by values at the high end of those ranges. ${ }^{14 a, b}$

The NMR spectra of tellurium- or selenium-containing imidodiphosphinates have provided an initial indication of unexpected structures. For example, the ${ }^{31} \mathrm{P}$ NMR spectra on the monochalcogenides $\mathbf{1 a}$ and $\mathbf{1 b}$ showed one resonance with ${ }^{1} J(\mathrm{PE})$ values consistent with terminal a $\mathrm{P}=\mathrm{E}$ bond and a second resonance which revealed ${ }^{1} \mathrm{~J}(\mathrm{PH})=$ 440-445 Hz, signifying the formation of the P-H tautomer. ${ }^{6}$ The NMR spectra of the dimeric structures shown in Chart 1 are also revealing. At room temperature the ${ }^{31} \mathrm{P} \mathrm{NMR}$ spectra of the dichalcogenides (DCs), e.g. $4 a\left(E=E^{\prime}=T e ; R={ }^{i} P r\right)$ exhibit a broad, unresolved resonance indicative of a fluxional process. At low temperatures a pair of mutually coupled doublets is resolved with ${ }^{1} J(\mathrm{PTe})=1500$ and $1026 \mathrm{~Hz}$, consistent with the solid-state structure. ${ }^{6}$ By contrast, the observation of four resonances in the low 
temperature ${ }^{31} \mathrm{P}$ NMR spectrum of the tert-butyl derivative $\mathbf{5 \mathbf { a } ^ { \prime }}$ was a signal of a different structure, subsequently shown to be a contact ion pair (CIPs, Chart 1). ${ }^{9}$

${ }^{31} \mathrm{P}$ NMR spectra are also diagnostic of the purity of the Li derivatives of mixed chalcogen ligands, $\mathbf{2 b}$ and $\mathbf{2 c}$, which exhibit characteristic satellite peaks, since the presence of the corresponding symmetrical ligands is readily detected. ${ }^{10}$ In contrast to the behavior of the mixed selenotellurophosphinate $\left[\mathrm{Ph}_{2} \mathrm{P}(\mathrm{Se}) \mathrm{Te}\right]\left[\left[\mathrm{Li}(\mathrm{THF})_{2}(\mathrm{TMEDA})\right],{ }^{15}\right.$ no chalcogen exchange was detected in the NMR spectra of $\mathbf{2 b}$ and $\mathbf{2 c} .^{11}$ The formation of the Te-Te bonded isomer $\mathbf{4 b}$ from oxidation of $\mathbf{2} \mathbf{b}$ was clearly indicated by the observation of a terminal $\mathrm{P}=\mathrm{Se}$ coupling of $639 \mathrm{~Hz} .^{11}$

\section{Coordination Chemistry}

4.1. Complexes of $\left[\mathbf{N}\left(\mathbf{P}^{\mathbf{P}} \mathbf{P r}_{2} \mathbf{T e}\right)_{2}\right]^{-}$. Although the primary incentive for the preparation of homoleptic complexes of the anion $\left[\mathrm{N}\left(\mathrm{P}^{\mathrm{i}} \mathrm{Pr}_{2} \mathrm{Te}\right)_{2}\right]^{-}$was the generation of new singlesource precursors to metal tellurides, we found that this Te,Te'-chelating ligand exhibits significant differences in coordination behavior in comparison with the well-studied bonding patterns of the analogous disulfido and diselenido-imidodiphosphinate ligands.

Metathetical reactions between $\mathbf{2 a}$ and a variety of main group, transition-metal, lanthanide and actinide halides produce homoleptic complexes $\mathrm{M}\left[\mathrm{N}\left(\mathrm{P}^{\mathrm{i}} \mathrm{Pr}_{2} \mathrm{Te}\right)_{2}\right]_{\mathrm{n}}{ }^{16}$ with square planar $\left(\mathbf{8}, \mathrm{n}=2 ; \mathrm{M}=\mathrm{Ni},{ }^{17} \mathrm{Pd}^{18}{ }^{18} \mathrm{Pt}^{18}\right)$, distorted tetrahedral $(\mathbf{9}, \mathrm{n}=2 ; \mathrm{M}=\mathrm{Zn}, \mathrm{Cd}$, $\mathrm{Hg}),{ }^{8}$ or distorted octahedral $\left(\mathbf{1 0}, \mathrm{n}=3 ; \mathrm{M}=\mathrm{Sb},{ }^{8} \mathrm{Bi}^{8}{ }^{8} \mathrm{La},{ }^{19 \mathrm{a}} \mathrm{U},{ }^{19 \mathrm{a}} \mathrm{Pu},{ }^{19 b} \mathrm{Ce}^{19 b}\right)$ geometries. DFT calculations indicate a high degree of covalency for the U-Te bonds in the uranium(III) complex 10d, ${ }^{19 \mathrm{~b}}$ the first example of a molecular compound with actinide-tellurium bonds. The square-planar structure of $\mathbf{8 a}$ is maintained in solution, 
whereas the sulfur analogue adopts a tetrahedral geometry and the corresponding selenium complex has been isolated as both tetrahedral and square-planar stereoisomers in the solid state. ${ }^{17}$ Homoleptic group 10 complexes of mixed chalcogen ligands $\mathrm{M}\left[\mathrm{N}\left(\mathrm{P}^{\mathrm{i}} \mathrm{Pr}_{2} \mathrm{Te}\right)\left(\mathrm{P}^{\mathrm{i}} \mathrm{Pr}_{2} \mathrm{E}\right)\right]_{2}(\mathrm{M}=\mathrm{Ni} . \mathrm{Pd}, \mathrm{Pt} ; \mathrm{E}=\mathrm{S}, \mathrm{Se})$ are prepared by metathesis between the $\mathrm{Li}$ reagents $\mathbf{2 b}$ or $\mathbf{2} \mathbf{c}$ and $\mathrm{NiBr}_{2}(\mathrm{DME})^{20}(\mathrm{DME}=$ dimethoxyethane $)$ or $\mathrm{MCl}_{2}(\mathrm{COD})$ $(\mathrm{M}=\mathrm{Pd}, \mathrm{Pt} ; \mathrm{COD}=1,5$-cyclooctadiene $) .{ }^{18}$ The $\mathrm{Ni}(\mathrm{II})$ complexes are isolated as the square-planar trans isomers ${ }^{20}$ while the Pd and Pt complexes exist as a mixture of $c i s$ and trans isomers in solution. ${ }^{18}$

The homoleptic group 14 complexes $\mathrm{M}\left[\mathrm{N}\left(\mathrm{P}^{\mathrm{i}} \mathrm{Pr}_{2} \mathrm{Te}\right)_{2}\right]_{2} \quad(\mathbf{1 1 a}, \mathrm{M}=\mathrm{Sn} ; \mathbf{1 1 b}, \mathrm{M}=$ $\mathrm{Pb}$ ) adopt pseudo-trigonal bipyramidal structures, reflecting the stereochemical influence of the lone pair on the metal center; weak intermolecular $\mathrm{M} \cdots \mathrm{Te}$ interactions result in dimeric arrangements. ${ }^{21}$ The thallium(I) complex $\left\{\mathrm{Tl}\left[\mathrm{N}\left(\mathrm{TeP}^{\mathrm{i}} \mathrm{Pr}_{2}\right)_{2}\right]\right\}_{\infty}$, which is prepared from 2a and TlOEt, is the first example of a molecular complex containing Tl-Te bonds. It is comprised of infinite chains linked by $\mathrm{Tl} \cdots \mathrm{Te}$ interactions in which six-coordinate $\mathrm{Tl}$ centers are bridged by two different $\left[\mathrm{N}\left(\mathrm{P}^{\mathrm{i}} \mathrm{Pr}_{2} \mathrm{Te}\right)_{2}\right]^{-}$ligands arranged approximately perpendicular to each other. ${ }^{22}$ The selenium analogue $\left\{\mathrm{Tl}\left[\mathrm{N}\left(\mathrm{SeP}^{\mathrm{i}} \mathrm{Pr}_{2}\right)_{2}\right]\right\}_{\infty}$ has a similar polymeric structure with both 5- and 6-coordinate $\mathrm{Tl}$ centers, whereas the sulfur congener $\left\{\mathrm{Tl}\left[\mathrm{N}\left(\mathrm{SP}^{\mathrm{i}} \mathrm{Pr}_{2}\right)_{2}\right]\right\}_{\infty} \quad$ is a ladder-like polymer with 4-coordinate $\mathrm{Tl}$ centers, cf. $\left\{\mathrm{K}\left[\mathrm{N}\left(\mathrm{SPPh}_{2}\right)_{2}\right]\right\}_{\infty}{ }^{23}$

Coinage metal complexes of the ditellurido anion $\left[\mathrm{N}\left(\mathrm{P}^{\mathrm{i}} \mathrm{Pr}_{2} \mathrm{E}\right)_{2}\right]^{-}(\mathrm{E}=\mathrm{Te})$ exhibit interesting structural differences when compared to the analogous complexes of the disulfido $(\mathrm{E}=\mathrm{S})$ and diselenido $(\mathrm{E}=\mathrm{Se})$ ligands as a result of the propensity of the ditellurido ligand to adopt a doubly bridging bonding mode. ${ }^{24}$ One of the ligands in the 
trimeric copper(I) complex $\left\{\mathrm{Cu}\left[\mathrm{N}\left(\mathrm{P}^{\mathrm{i}} \mathrm{Pr}_{2} \mathrm{Te}\right)_{2}\right]\right\}_{3}$ (12) exhibits this behavior resulting in two short (ca. $2.63 \AA$ ) and one long (ca. $3.58 \AA$ ) $\mathrm{Cu}$-Cu distance, whereas the analogous disulfido and diselenido ligands in $\left\{\mathrm{Cu}\left[\mathrm{N}\left(\mathrm{P}^{\mathrm{i}} \mathrm{Pr}_{2} \mathrm{E}\right)_{2}\right]\right\}_{3}$ (13a,b) all behave as singly bridging ligands and the three $\mathrm{Cu}$ atoms form an equilateral triangle. ${ }^{25,} 26$ The greater flexibility of the ditellurido ligand $\left[\mathrm{N}\left(\mathrm{P}^{\mathrm{i}} \mathrm{Pr}_{2} \mathrm{Te}\right)_{2}\right]^{-}$is also evident in the silver(I) complex $\left\{\operatorname{Ag}\left[\mathrm{N}\left(\mathrm{P}^{\mathrm{i}} \mathrm{Pr}_{2} \mathrm{Te}\right)_{2}\right]\right\}_{6}(\mathbf{1 4 a})$, which forms a hexamer comprised of a twelve-membered $\mathrm{Ag}_{6} \mathrm{Te}_{6}$ ring, ${ }^{24}$ whereas the selenium analogue is trimeric $\left\{\mathrm{Ag}\left[\mathrm{N}\left(\mathrm{P}^{\mathrm{i}} \mathrm{Pr}_{2} \mathrm{Se}\right)_{2}\right]\right\}_{3}$, cf. 13a. ${ }^{25}$ A change of the substituents on phosphorus from iso-propyl to phenyl in the ditellurido ligand gives rise to a profound structural change. The complex $\left\{\mathrm{Ag}\left[\mathrm{N}\left(\mathrm{PPh}_{2} \mathrm{Te}\right)_{2}\right]\right\}_{4}(\mathbf{1 4 b})$ adopts a tetrameric structure in the form of a centrosymmetric, chair-shaped eightmembered $\mathrm{Ag}_{4} \mathrm{Te}_{4}$ ring. ${ }^{24}$ The doubly bridging mode of one of the $\left[\mathrm{N}\left(\mathrm{PPh}_{2} \mathrm{Te}\right)_{2}\right]^{-}$ligands in the tetramer creates a 4-coordinate environment for one of the $\mathrm{Ag}$ atoms and short transannular Ag $\cdots \mathrm{Ag}$ contacts between the 3-coordinate Ag centers. The distortion of the latter from trigonal planar geometry $\left(\Sigma<\mathrm{Ag}=345^{\circ}\right)$ may indicate a metallophilic interaction.

4.2. Complexes of $\left[\mathrm{TeP}^{\mathrm{i}} \mathrm{Pr}_{2} \mathrm{~N}^{\mathrm{i}} \mathrm{Pr}_{2} \mathrm{P}\right]^{-}$. Although it is thermally unstable (due to disproportionation), we have demonstrated that the lithium reagent $\operatorname{Li}\left[\operatorname{TeP}^{i} \operatorname{Pr}_{2} \mathrm{~N}^{i} \mathrm{Pr}_{2} \mathrm{P}\right]$ (3a) can be generated by lithiation of $1 \mathbf{a}$ at $-78{ }^{\circ} \mathrm{C}$ (Scheme 1) and, subsequently, used for in situ metathesis with metal halides. In this way homoleptic complexes of the type $\mathrm{M}\left(\mathrm{TeP}^{\mathrm{i}} \mathrm{Pr}_{2} \mathrm{~N}^{\mathrm{i}} \mathrm{Pr}_{2} \mathrm{P}\right)_{2}$ with distorted tetrahedral $(\mathrm{M}=\mathrm{Zn}, \mathrm{Cd}, \mathrm{Hg})^{27}$ or square-planar $(\mathrm{M}=$ $\mathrm{Ni},{ }^{20} \mathrm{Pd},{ }^{18} \mathrm{Pt}^{18}$ ) structures are obtained via metathesis. The Ni complex is formed exclusively as the trans isomer whereas the Pd analogue exists as a mixture of the 
isomers cis-16a and trans-16a, ${ }^{18}$ which can be separated by fractional crystallization. In the case of $\mathrm{Pt}$ the major product from the reaction with $\mathrm{PtCl}_{2}(\mathrm{COD})$ is the unusual complex $\operatorname{Pt}\left[\left(\mathrm{P}^{\mathrm{i}} \mathrm{Pr}_{2}\right)\left(\mathrm{TeP}^{\mathrm{i}} \mathrm{Pr}_{2}\right) \mathrm{N}\right]\left[\sigma: \eta^{2}-\mathrm{C}_{8} \mathrm{H}_{12}\left(\mathrm{P}^{\mathrm{i}} \mathrm{Pr}_{2} \mathrm{NP}^{\mathrm{i}} \mathrm{Pr}_{2} \mathrm{Te}\right)\right] \quad$ (17) resulting from nucleophilic attack of the phosphorus(III)-centered anion $\left[\mathrm{TeP}^{\mathrm{i}} \operatorname{Pr}_{2} \mathrm{~N}^{\mathrm{i}} \mathrm{Pr}_{2} \mathrm{P}\right]^{-}$on the coordinated COD ligand; trans- $\mathbf{1 6 \mathbf { b }}$ is the minor product of this reaction. ${ }^{18}$

The group 11 complexes $\left\{\mathrm{M}\left(\mathrm{TeP}^{\mathrm{i}} \mathrm{Pr}_{2} \mathrm{~N}^{\mathrm{i}} \mathrm{Pr}_{2} \mathrm{P}\right)\right\}_{3}(\mathbf{1 5 a}, \mathrm{M}=\mathrm{Cu} ; \mathbf{1 5 b}, \mathrm{M}=\mathrm{Ag})$ have particularly interesting trimeric frameworks in which the tellurium centers bridge two metal atoms to give highly distorted chair-like $\mathrm{M}_{3} \mathrm{Te}_{3}$ rings with short $\mathrm{M}-\mathrm{M}$ distances. ${ }^{28}$ During the X-ray structural investigations of $\mathbf{1 5 a}$, we observed that air oxidation of the yellow crystals in Paratone oil gave a few colorless crystals of the mixed chalcogen complex $\left\{\mathrm{Cu}\left(\mathrm{TeP}^{\mathrm{i}} \mathrm{Pr}_{2} \mathrm{~N}^{\mathrm{i}} \mathrm{Pr}_{2} \mathrm{PO}\right)\right\}_{3}{ }^{28}$ This fascinating transformation (oxygen insertion into a $\mathrm{Cu}-\mathrm{P}$ bond) inspired us to investigate the reactions of the labile trimer 15a with chalcogens. ${ }^{28}$ By choosing appropriate conditions, we found that the series of mixed chalcogen complexes $\left\{\mathrm{Cu}\left(\mathrm{TeP}^{\mathrm{i}} \mathrm{Pr}_{2} \mathrm{~N}^{\mathrm{i}} \mathrm{Pr}_{2} \mathrm{PE}\right)\right\}_{3}(\mathbf{1 8 a}, \mathrm{E}=\mathrm{O} ; \mathbf{1 8 b}, \mathrm{E}=\mathrm{S} ; \mathbf{1 8 c}, \mathrm{E}=\mathrm{Se})$ are formed upon treatment of 15a with $\mathrm{Me}_{3} \mathrm{NO}$, elemental sulfur or red selenium, respectively (eq. 3) ${ }^{28}$ The complex 18a features the first example of a Te,O-centered ligand of this type. The complexes 18a-c all exhibit a trinuclear structure with the tellurium centers occupying the bridging positions to give a chair-like $\mathrm{Cu}_{3} \mathrm{Te}_{3}$ ring in which the trigonal planar copper centers form an approximately equilateral triangle.

4.3. Intramolecular Oxidative Additions. We observed another manifestation of the unique behavior of the ditellurido ligands $\left[\mathrm{N}\left(\mathrm{PR}_{2} \mathrm{Te}\right)_{2}\right]^{-}$in the attempted synthesis of homoleptic complexes of gallium(III), ${ }^{29}$ indium(III), ${ }^{29}$ and gold(I) $;{ }^{30}$ for all three metals a 
tellurium-transfer process occurs to give novel metal-tellurium rings. Thus the reaction of 2a with gallium trichloride produced the dimeric $\mathrm{Ga}^{\mathrm{III}}$ complex $\{\mathrm{Ga}(\mu$ $\left.\mathrm{Te})\left[{ }^{\mathrm{i}} \mathrm{Pr}_{2} \mathrm{PN}^{\mathrm{i}} \mathrm{Pr}_{2} \mathrm{PTe}\right]\right\}_{2}$ (19) and the ditelluride dimer 4a. A possible pathway for the formation of $\mathbf{1 9}$ involves reductive elimination of $\mathbf{4 a}$ from the homoleptic $\mathrm{Ga}^{\mathrm{III}}$ complex $\mathrm{Ga}\left[\mathrm{N}\left(\mathrm{P}^{\mathrm{i} P r} \mathrm{Te}_{2}\right)_{2}\right]_{3}$ (20) to give the $\mathrm{Ga}^{\mathrm{I}}$ complex $\mathrm{Ga}\left[\mathrm{N}\left(\mathrm{P}^{\mathrm{i} P r} \mathrm{Te}_{2}\right)_{2}\right]$ (21), which undergoes tellurium transfer (intramolecular oxidative addition) to give the $\mathrm{Ga}_{2} \mathrm{Te}_{2}$ dimer 19 via the unstable gallatellurone 22 (Scheme 3). Both cis and trans isomers of 19 are present in solutions, but the trans isomer crystallizes preferentially. ${ }^{29}$

We also discerned intramolecular oxidative addition in the attempted metathesis of $2 \mathbf{a}$ with indium trichloride, which produced a low yield of the trimeric complex $\{\operatorname{In}(\mu-$ $\left.\mathrm{Te})\left[\mathrm{N}\left({ }^{\mathrm{i}} \mathrm{Pr}_{2} \mathrm{PTe}\right)_{2}\right]\right\}_{3}$ (23a) comprised of a central $\mathrm{In}_{3} \mathrm{Te}_{3}$ ring. ${ }^{29}$ Subsequently, we devised a high-yield synthesis of this novel $\mathrm{In}^{\mathrm{III}}$ complex involving the metathesis of $\mathrm{In}(\mathrm{I}) \mathrm{Cl}$ with 2a in the presence of elemental tellurium (eq. 2). The gallium analogue $\mathbf{2 3 \mathbf { b }}$ is obtained in a similar manner by using $\mathrm{GaI}$ instead of $\mathrm{InCl}^{29}$

The strongly reducing nature of the ditellurido anions $\left[\mathrm{N}\left(\mathrm{PR}_{2} \mathrm{Te}\right)_{2}\right]^{-}$is evident in the reaction of $\mathbf{2 a}$ with gold(I) chloride, which rapidly produces a gold mirror. ${ }^{24} \mathrm{We}$ found that this process can be prevented by the addition of a two-electron donor prior to the metathesis. Thus, the reaction of $\mathbf{2 a}$ with $\mathrm{AuCl}$ in the presence of triphenylphosphine, produces the monomeric complex $\mathrm{Au}\left(\mathrm{PPh}_{3}\right)\left[\mathrm{N}\left(\mathrm{P}^{\mathrm{i}} \mathrm{Pr}_{2} \mathrm{Te}\right)_{2}\right](\mathbf{2 4}) .{ }^{24}$ Intriguingly, the use of $(\mathrm{THT}) \mathrm{AuCl}(\mathrm{THT}=$ tetrahydrothiophene) as the source of gold(I) results in the formation of the dimeric gold(III) complexes $\left\{\mathrm{Au}(\mu-\mathrm{Te})\left[\mathrm{R}_{2} \mathrm{PNR}_{2} \mathrm{PTe}\right]\right\}_{2}(\mathbf{2 5})^{30}$ as a mixture of cis and trans isomers; the trans isomer crystallizes preferentially. The formation of the central $\mathrm{Au}_{2} \mathrm{Te}_{2}$ ring formally involves an intramolecular oxidative addition reminiscent of 
that proposed for the generation of the $\mathrm{Ga}_{2} \mathrm{Te}_{2}$ ring (Scheme 3). Interestingly, in the case of the $\mathrm{Au}-\mathrm{Te}$ system, this process is reversible upon addition of $\mathrm{PPh}_{3}$ to give the monomeric gold(I) complex 24 (eq. 3). ${ }^{30}$

4.4 Solution NMR Studies. ${ }^{31} \mathrm{P}$ NMR studies of coordination complexes of ditelluroimidodiphosphinates have revealed the presence of isomeric or oligomeric species in solution. For example, cis and trans isomers are apparent for the Ga complex 19 (Scheme 3) ${ }^{29}$ and the Au complexes 25 (Eq. 3). ${ }^{30}$ In the latter case the determination of the solid-state ${ }^{31} \mathrm{P}$ NMR spectrum of $\mathbf{2 5}\left(\mathrm{R}={ }^{\mathrm{i}} \mathrm{Pr}\right)$ facilitated the assignment of the resonances in the solution spectrum to the individual isomers. ${ }^{30}$ NMR spectra also provide decisive structural information for the series of $\mathrm{Ni}(\mathrm{II})$ complexes $\mathrm{Ni}\left[\mathrm{N}\left(\mathrm{P}^{\mathrm{i}} \mathrm{Pr}_{2} \mathrm{E}\right)_{2}\right]_{2}$

$(\mathrm{E}=\mathrm{S}, \mathrm{Se}, \mathrm{Te})$ in solution. ${ }^{17}$ Although the Se analogue exists as either a square-planar (diamagnetic) or a tetrahedral (paramagnetic) complex in the solid state, both isomers exhibit a paramagnetically shifted ${ }^{31} \mathrm{P}$ NMR resonance indicating only the $\mathrm{T}_{\mathrm{d}}$ isomer prevails in solution; the $\mathrm{S}$ and $\mathrm{Te}$ analogues maintain their tetrahedral and square-planar structures, respectively. ${ }^{17}$ Additionally, the low-temperature ${ }^{31} \mathrm{P}$ NMR spectra of $\mathrm{d}_{8}$-THF solutions of the $\mathrm{Cu}(\mathrm{II})$ and $\operatorname{Ag}(\mathrm{I})$ complexes $\mathbf{1 5 a}, \mathbf{b}$ yielded evidence that these species, which are trimeric in the solid state, form a mixture of oligomers which are in dynamic equilibrium. $^{28}$

\section{Single-Source Precursors for Metal Tellurides}

Current interest in metal tellurides, e.g. $\mathrm{CdTe}, \mathrm{Sb}_{2} \mathrm{Te}_{3}, \mathrm{PbTe}$, emanates from their potential uses as low-band-gap semiconducting materials in solar cells, thermoelectric 
devices, and telecommunications. Metal complexes of a number of tellurium-centered ligands have been investigated as single-source precursors of binary metal tellurides. These include the group 14 tellurolates $\mathrm{M}\left[\mathrm{Te}\left\{\mathrm{Si}\left(\mathrm{SiMe}_{3}\right)_{3}\right\}\right]_{2} \quad(\mathrm{M}=\mathrm{Sn}, \mathrm{Pb}),{ }^{31}$ the N,Techelated complexes $\mathrm{M}\left[\mathrm{NR}(\mathrm{Te}) \mathrm{P}^{\mathrm{t}} \mathrm{Bu}_{2}\right]_{2}\left(\mathrm{M}=\mathrm{Zn}, \mathrm{Cd} ; \mathrm{R}={ }^{\mathrm{i}} \mathrm{Pr}, \mathrm{Cy}\right),{ }^{32}$ and the six-membered ring $\left(\mathrm{Bn}_{2} \mathrm{SnTe}\right)_{3}(\mathrm{Bn}=$ benzyl $) .{ }^{33} \mathrm{In}$ all these examples thermolysis produced thin films of metal tellurides that were contaminated with small amounts of carbon and/or the metal. More recently, an isopropylgermanium tellurolate has been used to generate GeTe thin films by using CVD techniques. ${ }^{34}$ An evaluation of the suitability of the homoleptic ditelluridoimidodiphosphinate complexes of group 11,12,14 and 15, as well as the group 13 complexes 23a,b, as single-source precursors for metal tellurides using the AACVD technique has been carried out in collaboration with O'Brien and co-workers. ${ }^{35}$ The results are summarized in Table 1, which shows that this method is successful for producing pure thin films of $\mathrm{CdTe}_{2},{ }^{36} \mathrm{Sb}_{2} \mathrm{Te}_{3},{ }^{37} \mathrm{In}_{2} \mathrm{Te}_{3},{ }^{38}$ and $\mathrm{PbTe}^{21}$ under appropriate conditions. For some precursors, however, AACVD produces only elemental tellurium $(9 c, 10 b, 11 a)$ or a mixture of a metal telluride and tellurium $(\mathbf{1 2}, \mathbf{2 3 b}, \mathbf{2 4})$. The formation of elemental tellurium in some cases is perhaps not unexpected in view of the high Te:M ratio in the precursors, however the use of a homoleptic mercury complex of the monotellurido ligand $\left[\mathrm{TeP}^{\mathrm{i}} \mathrm{Pr}_{2} \mathrm{~N}^{\mathrm{i}} \mathrm{Pr}_{2} \mathrm{P}\right]^{-}$did not produce pure $\mathrm{HgTe}$.

Attempts to produce ternary nickel chalcogenides from the mixed chalcogen complexes $\mathrm{Ni}\left[\mathrm{N}\left({ }^{i} \mathrm{Pr}_{2} \mathrm{PSe}\right)\left({ }^{i} \mathrm{Pr}_{2} \mathrm{PE}\right)\right]_{2}$ generated the binary chalcogenide $\mathrm{NiTe}_{2}$ by AACVD when $\mathrm{E}=\mathrm{Te}^{20}$ or both nickel phosphide $\left(\mathrm{Ni}_{2} \mathrm{P}\right)$ and nickel selenide $\left(\mathrm{Ni} 0_{0.85} \mathrm{Se}\right)$ by LPCVD for $\mathrm{E}=\mathrm{S} .{ }^{39}$ The reason for the preferential formation of the heavier chalcogenide from these SSPs has not been established. 


\section{Conclusions}

In summary, comprehensive investigations of the redox behavior and coordination complexes of anionic tellurium-centered imidodiphosphinates have provided new insights into the chemistry of this well-established class of inorganic ligand. One-electron oxidation provides a variety of dimers whose structures are influenced by the nature of the chalcogen as well as the organic substituent on phosphorus; two-electron oxidation generates novel cyclic cations. In conjunction with DFT calculations, the structural data for these dimers and cations have enhanced our understanding of chalcogen-chalcogen bonding. Significant differences in the coordination behavior of the tellurium-centered ligands compared to that of their lighter chalcogen analogues was observed as a result of (a) the larger size of tellurium and (b) the weakness of P-Te bonds. The former is manifested in the tendency for the tellurium ligands to adopt a doubly bridging coordination mode leading to unprecedented structures and, in the case of coinage metals, the possibility of metallophilic interactions. The lability of $\mathrm{P}-\mathrm{Te}$ bonds is demonstrated by the occurrence of tellurium-transfer processes (intramolecular oxidative additions) that generate novel metal-tellurium rings. It is also evident in the use of metal complexes as single-source precursors to thin films of binary metal tellurides. The majority of our work has been carried out on ligands with isopropyl (or tert-butyl) substitutents on phosphorus. However, preliminary investigations presage that significantly different chemistry will be observed for the phenyl-substituted analogues. ${ }^{13 \mathrm{~b}}$ 
All of this work was funded by NSERC (Canada). Pivotal contributions to the early investigations by Drs Glen G. Briand, Dana J. Eisler and May C. Copsey and the collaboration with Prof. P. O'Brien and Dr M. Afzaal (University of Manchester, UK) on the generation of metal tellurides from single-source precursors are gratefully acknowledged.

\section{References}

(1) Schmidpeter, A.; Böhm, R.; Groeger, H. Imidodiphosphinatometal chelates, neutral complexes with carbon-free chelate rings. Angew. Chem., Int. Ed. 1964, 3, 704-704.

(2) For recent reviews, see (a) Silvestru, C.; Drake, J. E. Tetraorganodichalcogenoimidodiphosphorus acids and their main group metal derivatives. Coord. Chem. Rev., 2001, 223, 117-216. (b) Haiduc, I. Dichalcogenoimidodiphosph(in)ate ligands, Comprehensive Coordination Chemistry II, Ed. Lever, A. B. P., Elsevier Pergamon, Amsterdam, Oxford, 2004, Vol. 1, pp. 323-347.

(3) For selected examples, see (a) Afzaal, M.; Crouch, D.; Malik, M. A.; Motevalli, M.; O'Brien, P.; Park, J-H. Deposition of CdSe thin films using novel single-source precursors $\left\{\mathrm{MeCd}\left[\left(\mathrm{SeP}^{\mathrm{i}} \mathrm{Pr}_{2}\right)_{2} \mathrm{~N}\right\}_{2}\right.$. J. Mater. Chem. 2003, 13, 639-640. (b) Afzaal, M.; Ellwood, K.; Pickett, N. L.; O’Brien, P. Raftery, J.; Waters, J. Growth of lead chalcogenide thin films using single-source precursors. J. Mater. Chem. 2004, 14, 1310-1315. (c) Waters, J.; Crouch, D. J.; Raftery, J.; O'Brien, P. Deposition of bismuth chalcogenide thin films using novel single-source precursors by MOCVD, Chem. Mater. 2004, 16, 3289-3298.

(4) Crouch, D. J.; O’Brien, P.; Malik, M. A.; Skabara, P. J.; Wright, S. P. A onestep synthesis of CdSe quantum dots from a novel single source precursor. Chem. Commun. 2003, 1454-1455.

(5) (a) Bhattacharyya, P.; Novosad, J.; Phillips, J.; Slawin, A. M. Z.; Williams, D. J. Woollins, J. D. Bis(bidentate) complexes of imino(diphenylphosphine chalcogenides) $\left[\mathrm{M}\left\{\mathrm{N}\left(\mathrm{XPPh}_{2}\right)_{2}\right\}_{2}\right](\mathrm{X}=\mathrm{S}$ or $\mathrm{Se} ; \mathrm{M}=\mathrm{Ni}$, $\mathrm{Pd}$ or Pt). J. Chem. Soc. Dalton Trans. 1995, 1607-1613. (b) Cupertino, D.; Birdsall, D. J.; Slawin, A. M. Z.; Woollins, J. D. The preparation and coordination chemistry of ${ }^{\mathrm{i}} \operatorname{Pr}_{2} \mathrm{P}(\mathrm{E}) \mathrm{NHP}\left(\mathrm{E}^{\prime}\right)^{\mathrm{i}} \operatorname{Pr}_{2}\left(\mathrm{E}, \mathrm{E}^{\prime}=\mathrm{Se} ; \mathrm{E}=\mathrm{Se}, \mathrm{E}^{\prime}=\mathrm{S} ; \mathrm{E}=\mathrm{S}, \mathrm{E}^{\prime}=\mathrm{O} ; \mathrm{E}, \mathrm{E}^{\prime}=\mathrm{O}\right)$. Inorg. Chim. Acta, 1999, 290, 1-7. 
(6) Chivers, T.; Eisler, D.; Ritch, J. S.; Tuononen, H. M. An unusual ditelluride: synthesis, molecular and electronic structures of $\left(\mathrm{TeP}^{\mathrm{i}} \operatorname{Pr}_{2} \mathrm{~N}^{\mathrm{i}} \operatorname{Pr}_{2} \mathrm{PTe}-\right)_{2}$. Angew. Chem., Int. Ed. 2005, 44, 4953-4956.

(7) Chivers, T.; Parvez, M.; Briand, G.G. A new approach to metallated imido and amido tellurophosphoranes. Angew. Chem. Int. Ed. 2002, 41, 3468-3470.

(8) Chivers, T.; Eisler, D. J.; Ritch, J. S. Synthesis and structures of $\mathrm{M}\left[\mathrm{N}\left(\mathrm{TePPr}_{2}{ }_{2}\right)_{2}-T e, T e^{\prime}\right]_{\mathrm{n}}(\mathrm{n}=2, \mathrm{M}=\mathrm{Zn}, \mathrm{Cd}, \mathrm{Hg} ; \mathrm{n}=3, \mathrm{M}=\mathrm{Sb}, \mathrm{Bi})$ : the first ditelluroimidodiphosphinato $p$ - and $d$-block metal complexes. Dalton Trans. 2005, 2675-2677.

(9) Ritch, J. S.; Chivers, T.; Eisler, D. J.; Tuononen, H. M. Experimental and theoretical investigations of structural isomers of dichalcogenoimidodiphosphinate dimers: dichalcogenides or spirocyclic contact-ion pairs. Chem. Eur J. 2007, 13, 4643-4653.

(10) Robertson, S. D.; Chivers, T. Synthesis and NMR characterization of mixed chalcogenido PNP ligands containing tellurium: X-ray structures of $\mathrm{Se}^{\mathrm{i}} \mathrm{Pr}_{2} \mathrm{PNP}(\mathrm{H}){ }^{\mathrm{i}} \mathrm{Pr}_{2}, \quad\left[(\mathrm{TMEDA}) \operatorname{Li}\left(\mathrm{EP}^{\mathrm{i}} \mathrm{Pr}_{2}\right)\left(\mathrm{TeP}^{\mathrm{i}} \mathrm{Pr}_{2}\right)\right] \quad(\mathrm{E}=\mathrm{S}, \quad \mathrm{Se})$ and $\left[\mathrm{NaN}\left(\mathrm{EP}^{\mathrm{i}} \mathrm{Pr}_{2}\right)_{2}\right]_{\infty}(\mathrm{E}=\mathrm{Se}, \mathrm{Te})$. Dalton Trans. 2008, 1765-1772.

(11) Robertson, S. D.; Chivers, T.; Tuononen, H. M. Experimental and theoretical investigations of the redox behavior of the heterodichalcogenido Ligands $\left[\left(\mathrm{EP}^{\mathrm{i}} \mathrm{Pr}_{2}\right)\left(\mathrm{TeP}^{\mathrm{i}} \mathrm{Pr}_{2}\right) \mathrm{N}\right]^{-}(\mathrm{E}=\mathrm{S}, \mathrm{Se})$ : cyclic cations and acyclic dichalcogenide dimers. Inorg. Chem. 2008, 47, 10634-10643.

(12) Robertson, S. D.; Chivers, T.; Tuononen, H.M. Experimental and theoretical investigations of the contact ion pairs formed by reaction of the anions $\left[\left(\mathrm{EPR}_{2}\right)_{2} \mathrm{~N}\right]^{-}\left(\mathrm{R}={ }^{\mathrm{i}} \mathrm{Pr},{ }^{\mathrm{t}} \mathrm{Bu} ; \mathrm{E}=\mathrm{S}, \mathrm{Se}\right)$ with the cations $\left[(\mathrm{TePR})_{2} \mathrm{~N}\right]^{+}\left(\mathrm{R}={ }^{\mathrm{i}} \mathrm{Pr}\right.$, $\left.{ }^{t} \mathrm{Bu}\right)$, Inorg. Chem. 2009, 48, 6755-6762.

(13) (a) Konu, J.; Chivers, T.; Tuononen, H. M. The cyclic $\left[\mathrm{NP}_{2} \mathrm{E}_{2}\right]^{+}$cations $(\mathrm{E}=$ $\mathrm{Se}, \mathrm{Te}$ ): a new class of inorganic heterocycle. Chem. Commun. 2006, 16341636; (b)_Konu, J.; Chivers, T.; Tuononen, H. M. Synthesis, spectroscopic and structural investigation of the cyclic $\left[\mathrm{N}\left(\mathrm{PR}_{2} \mathrm{E}\right)\right]^{+}$cations $\left(\mathrm{E}=\mathrm{Se}, \mathrm{Te} ; \mathrm{R}={ }^{\mathrm{i}} \mathrm{Pr}\right.$, $\mathrm{Ph}$ ): effect of anion and R-group exchange, Inorg. Chem. 2006, 45, 1067810687.

(14) (a) Kuhn, N.; Henkel, G.; Schumann, H.; Fröhlich, R. The Nature of the bonding in phosphane telluride: an empirical NMR study and the crystal structure of ${ }^{\text {i }} \operatorname{Pr}_{3}$ PTe. Z. Naturforsch. 1990, 45b, 1010-1018; (b) Jones, C. H. W.; Sharma, R. D. ${ }^{125}$ Te NMR and Mössbauer spectroscopy of telluriumphosphine complexes and the tellurocyanates. Organometallics. 1987, 6, 1419-1423. 
(15) Davies, R. P.; Martinelli, M. G.; Wheatley, A. E. H.; White, A. J. P.; Williams, D. J. Structural studies of lithium telluro- and seleno-phosphorus compounds. Eur. J. Inorg. Chem. 2003, 3401-3416.

(16) Chivers, T.; Konu, J.; Ritch, J. S.; Eisler, D. J.; Copsey, M. C.; Tuononen, H. M. New tellurium-containing ring systems. J. Organomet Chem. 2007, 693, 2658-2668.

(17) Levesanos, N.; Robertson, S. D.; Maganas, D.; Raptopoulou, C. P.; Terzis, A.; Kyritsis, P.; Chivers, T. Ni[(EPi $\left.\left.\mathrm{Pr}_{2}\right)_{2} \mathrm{~N}\right]_{2}$ complexes: stereoisomers $(\mathrm{E}=\mathrm{Se})$ and square-planar coordination $(\mathrm{E}=\mathrm{Te})$. Inorg. Chem. 2008, 47, 2949-2951.

(18) Robertson, S. D.; Ritch, J. S.; Chivers, T. Palladium and platinum complexes of tellurium-containing imidodiphosphinate ligands: nucleophilic attack of $\mathrm{Li}\left[\left(\mathrm{P}^{\mathrm{i}} \mathrm{Pr}_{2}\right)\left(\mathrm{TeP}^{\mathrm{i}} \mathrm{Pr}_{2}\right) \mathrm{N}\right]$ on coordinated 1,5-cyclooctadiene, Dalton Trans. 2009, 8582-8592.

(19) (a) Gaunt, A. J.; Scott, B. L.; Neu, M. P. A molecular actinide-tellurium bond and comparison of bonding in $\left[\mathrm{M}^{\mathrm{III}}\left\{\mathrm{N}\left(\mathrm{P}^{\mathrm{i}} \mathrm{Pr}_{2} \mathrm{Te}\right)_{2}\right\}_{3}\right]$. Angew. Chem., Int. Ed. 2006, 45, 1638-1641; (b)_Gaunt, A. J.; Reilly, S. D.; Enriquez, A. E.; Scott, B. L.; Ibers, J. A.; Sekar, P.; Ingram, K. I. M.; Kaltsoyannis, N.; Neu, M. P. Experimental and theoretical comparison of actinide and lanthanide bonding in $\mathrm{M}\left[\mathrm{N}\left(\mathrm{EPR}_{2}\right)_{2}\right]_{3}$ complexes. $\left(\mathrm{M}=\mathrm{U}, \mathrm{Pu}, \mathrm{La}, \mathrm{Ce} ; \mathrm{E}=\mathrm{S}, \mathrm{Se}, \mathrm{Te} ; \mathrm{R}=\mathrm{Ph},{ }^{\mathrm{i}} \mathrm{Pr}\right.$, H). Inorg. Chem. 2008, 47, 29-41.

(20) Robertson, S. D.; Chivers, T.; Akhtar, J.; Afzaal, M.; O'Brien, P. Nickel(II) complexes of heterodichalcogenido and monochalcogenido imidodiphosphinate ligands: AACVD synthesis of nickel ditelluride, Dalton Trans. 2008, 7004-7011.

(21) Ritch, J.S.; Chivers, T.; Ahmad, K.; Afzaal, M.; O’Brien. P. Tin(II) and lead(II) complexes of tellurium-containing imidodiphosphinate ligands: synthesis, structures and preparation of two morphologies of phase-pure PbTe from a single-source precursor, Inorg. Chem, 2010, 48, 1198-1205.

(22) Ritch, J.S. Chivers, T. Thallium(I) complexes of dichalcogenido imidodiphosphinates $\left\{\mathrm{Tl}\left[\left(\mathrm{EP}^{\mathrm{i}} \mathrm{Pr}_{2}\right)_{2} \mathrm{~N}\right]\right\}_{n}(\mathrm{E}=\mathrm{Te}, \mathrm{Se}, \mathrm{S})$ : synthesis, NMR spectra and a structural comparison, Dalton Trans. 2010, 39, 1745-1750.

(23) Slawin, A. M. Z,; Ward, J.; Williams, D.J.; Woollins, J. D. X-ray structure of a potassium-sulfur ladder with strong $\mathrm{K} \cdots$ Aryl stabilising interactions, $J$. Chem. Soc. Chem. Commun. 1994, 421-422. 
(24) Copsey, M. C.; Panneerselvam, A.; Afzaal, M.; Chivers, T.; O'Brien, P. Syntheses, X-ray structures and AACVD studies of some group 11 ditelluroimidodiphosphinate complexes. Dalton Trans. 2007, 1528-1538.

(25) Afzaal, M.; Crouch, D. J.; O’Brien, P.; Raftery, J.; Skabara, P. J.; White, A, J. P.; Williams, D. J. The synthesis, X-ray structures and CVD studies of some group 11 complexes of iminobis(diisopropylphosphine selenides) and their use in the deposition of I/III/VI photovoltaic materials. J. Mater. Chem. 2004, 14, 233-237.

(26) Birdsall, D. J.; Slawin, A. M. Z.; Woollins, J. D. Synthesis and X-ray crystal structure of $\left[\mathrm{CuN}\left(\mathrm{R}_{2} \mathrm{PS}\right)_{2}\right]_{3}$. Inorg. Chem. 1999, 38, 4152-4155.

(27) Ritch, J. S.; Chivers, T. Coordination chemistry of a new $P, T e$-centred ligand: synthesis, NMR spectra and X-ray structures of $\mathrm{M}\left(\mathrm{TePPr}_{2}{ }_{2} \mathrm{NPPr}_{2}{ }_{2}\right)_{2}(\mathrm{M}=\mathrm{Zn}$, Cd, Hg). Dalton Trans. 2008, 957-962.

(28) Ritch, J. S.; Chivers, T. Group 11 complexes of a P,Te-centered ligand: synthesis, structures and chalcogen-insertion reactions. Inorg. Chem. 2009, 48, 3857-3865.

(29) Copsey, M.; Chivers, T. Formation of $\mathrm{Ga}_{2} \mathrm{Te}_{2}$ and $\mathrm{M}_{3} \mathrm{Te}_{3}$ rings $(\mathrm{M}=\mathrm{Ga}$, In) from reactions of sodium ditelluroimidodiphosphinate with group 13 halides. Chem. Commun. 2005, 4938-4940.

(30) Eisler, D. J.; Robertson, S. D.; Chivers, T. Gold complexes of ditelluroimidodiphosphinate ligands: reversible oxidation of $\mathrm{Au}(\mathrm{I})$ to $\mathrm{Au}(\mathrm{III})$ via insertion of gold into a phosphorus-tellurium bond. Can. J. Chem. 2009, 87, 39-46.

(31) Seligson, A. L.; Arnold, J. Synthesis, structure, and reactivity of homoleptic tin(II) and lead(II) chalcogenolates and their conversion to metal chalcogenides. X-ray crystal structures of $\mathrm{Sn}\left[\mathrm{Te}\left\{\mathrm{Si}\left(\mathrm{SiMe}_{3}\right)_{3}\right\}\right]_{2}$ and $\left(\mathrm{PMe}_{3}\right) \operatorname{Sn}\left[\mathrm{Te}\left\{\mathrm{Si}\left(\mathrm{SiMe}_{3}\right)_{3}\right\}\right]_{2}$, J. Am Chem. Soc. 1993, 115, 8214-8220.

(32) Bwembya, G. C.: Song, X.; Bochmann, M. Phosphinochalcogenoic amidato complexes of zinc and cadmium as novel single-source precursors for the deposition of metal selenide and telluride thin films. Chem. Vap. Deposition, 1995, $1,78-80$.

(33) Boudjouk, P.; Remington, M. P.; Grier, D. G.; Triebold, W.; Jarabek, B. R. Hexabenzylcyclotristannatellurane, $\left(\mathrm{Bn}_{2} \mathrm{SnTe}\right)_{3}$ : synthesis and structural characterization of an organometallic single-source precursor for phase-pure, polycrystalline SnTe,. Organometallics, 1999, 18, 4534-4537. 
(34) Chen, T.; Hunks, W.; Chen, P. S.; Stauf, G. T; Cameron, T. M.; Xu, C.; DiPasquale, A. G.; Rheingold, A. L. Insertion reactions of an aminogermylene and formation of a single-source precursor for GeTe thin films, Eur. J. Inorg. Chem. 2009, 2047-2049.

(35) For a review, see Ritch, J. S.; Afzaal, M.; Chivers, T.; O’Brien, P. The single molecular precursor approach to chalcogenide materials: iminobis(dialkylphosphine chalcogenides) as examples, Chem. Soc. Rev. 2007, 36, 1622-1631.

(36) Garje, S. S.; Ritch, J. S.; Eisler, D.J.; Afzaal, M.; O’Brien, P.; Chivers, T. Chemical vapour deposition of II-VI Semiconductor thin films using $\mathrm{M}\left[\left(\mathrm{TeP}^{\mathrm{i}} \mathrm{Pr}_{2}\right) \mathrm{N}_{2}(\mathrm{M}=\mathrm{Cd}, \mathrm{Hg})\right.$ as single-source precursors. J. Mater. Chem. 2006, 16, 966-969.

(37) Garje, S. S.; Eisler, D. J.; Ritch, J. S.; Afzaal, M; O’Brien, P.; Chivers, T._A new route to antimony telluride nanoplates from a single-source precursor. $J$. Am. Chem. Soc. 2006, 128, 3120-3121.

(38) Garje, S. S.; Copsey, M. C.; Afzaal, M.; O’Brien, P.; Chivers, T. Chemical vapour deposition of $\operatorname{In}_{2} \mathrm{Te}_{3}$ thin films using $\left\{\operatorname{In}(\mu-\mathrm{Te})\left[\mathrm{N}\left({ }^{i} \operatorname{Pr}_{2} \mathrm{PTe}\right)_{2}\right\}_{3}\right.$ as a single-source precursor. J. Mater. Chem. 2006, 16, 4542-4547.

(39) Panneerselvam, A.; Malik, M. A.; Afzaal, M.; O’Brien, P.; Helliwell, M. The chemical vapor deposition of nickel phosphide or selenide thin films from a single precursor. J. Am. Chem. Soc., 2008, 130, 2420-2421. 
Table 1. Formation of Metal Tellurides

from Single-Source (SS) Precursors

\begin{tabular}{|c|c|c|}
\hline Precursor & Products & Ref. \\
\hline $9 \mathbf{b}$ & Cubic CdTe & 36 \\
\hline $9 \mathrm{c}$ & Hexagonal Te & 36 \\
\hline $10 \mathbf{a}$ & Rhombohedral $\mathrm{Sb}_{2} \mathrm{Te}_{3}$ & 37 \\
\hline $11 \mathrm{~b}$ & $\mathrm{PbTe}$ & 21 \\
\hline 12 & Orthorhombic $\mathrm{CuTe}+\mathrm{Te}$ & 23 \\
\hline $14 a$ & $\mathrm{Ag}_{7} \mathrm{Te}_{4}+\mathrm{Te}$ & 23 \\
\hline 23a & Cubic $\operatorname{In}_{2} \mathrm{Te}_{3}$ & 38 \\
\hline $23 b$ & Cubic $\mathrm{Ga}_{2} \mathrm{Te}_{3}, \mathrm{GaTe}+\mathrm{Te}$ & 38 \\
\hline 24 & Monoclinic $\mathrm{AuTe}_{2}+\mathrm{Te}$ & 23 \\
\hline$a$ & Hexagonal $\mathrm{NiTe}_{2}$ & 20 \\
\hline
\end{tabular}

\section{Conspectus image.}

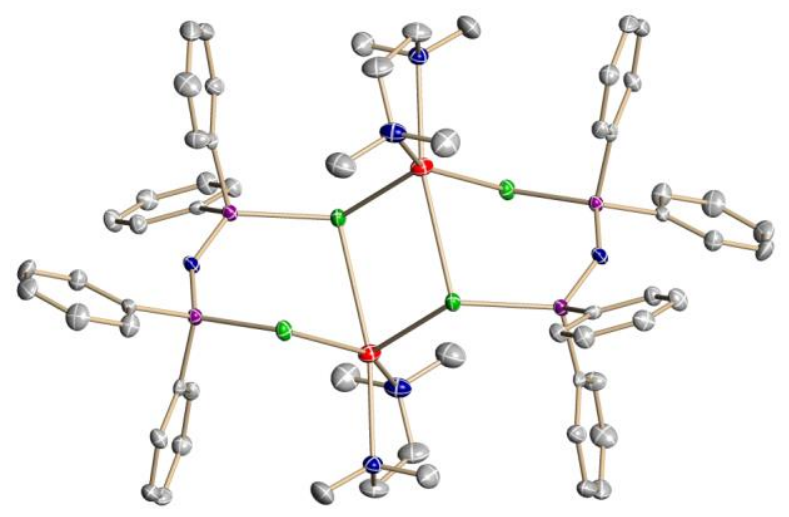

$\left\{\mathrm{Na}\left[(\mathrm{TePPh})_{2} \mathrm{~N}\right]\right\}_{2}$

sodium

tellurium

phosphorus

nitrogen

carbon 


\section{Scheme 1.}

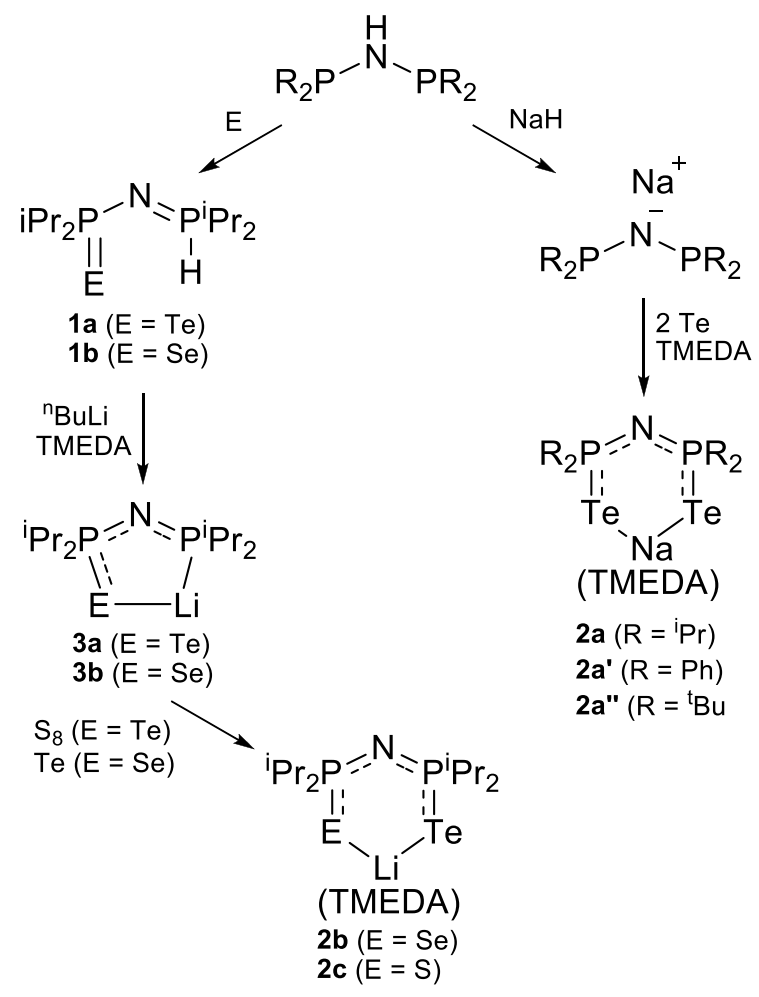

\section{Scheme 2.}

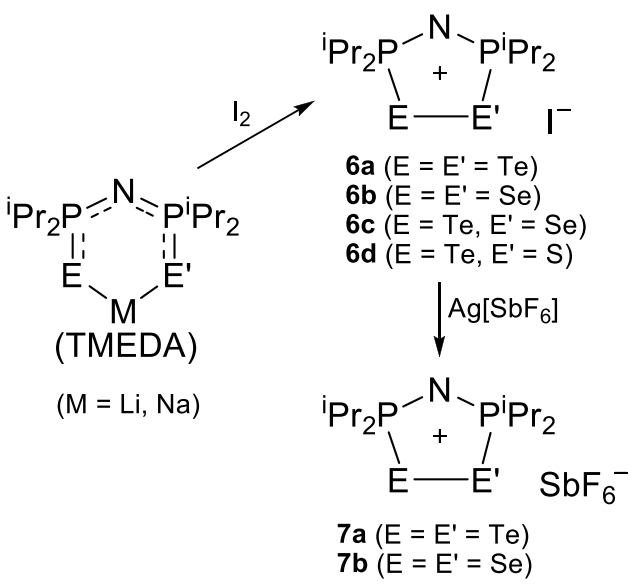




\section{Scheme 3}

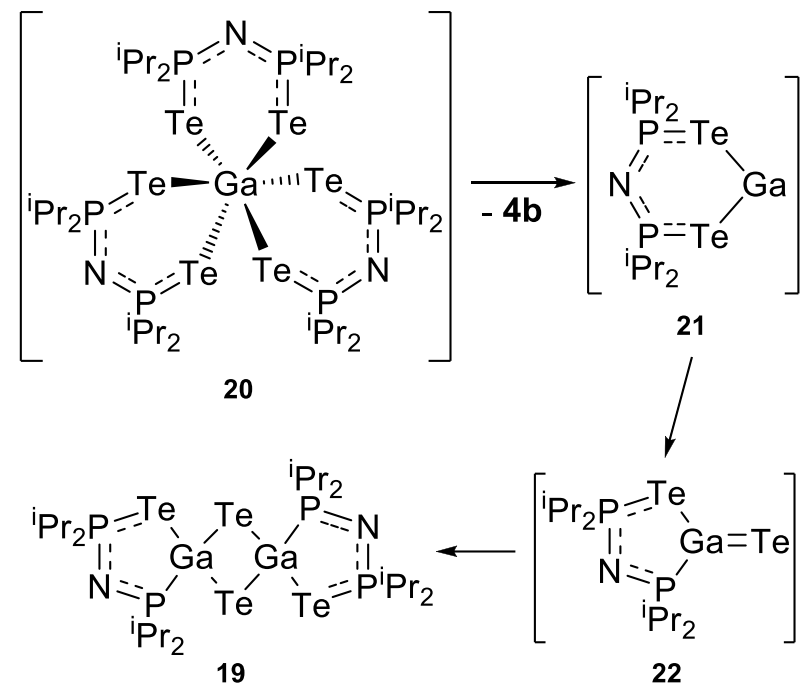

\section{Chart 1.}

\section{Dichalcogenides (DCs)}

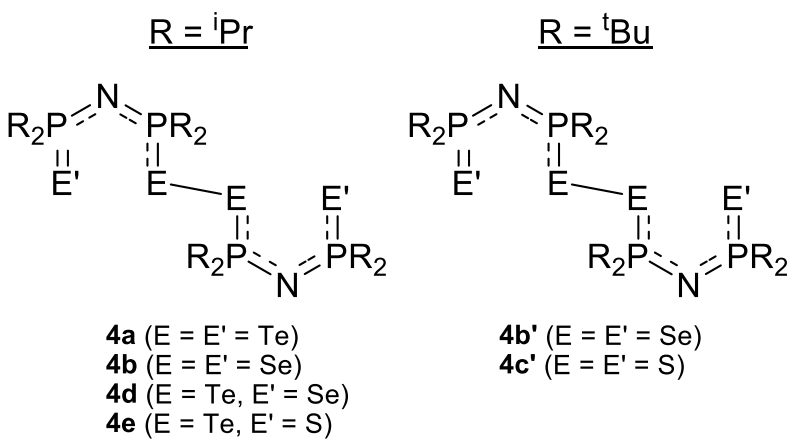

Contact lon Pairs (CIPs)

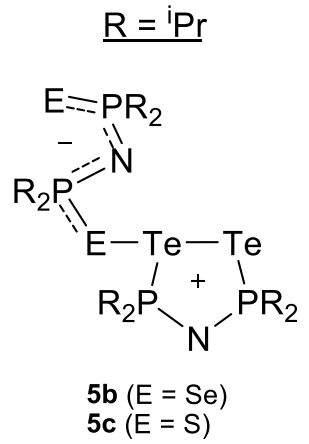

$$
\begin{aligned}
& \underline{\mathrm{R}}={ }^{\mathrm{t}} \mathrm{Bu}
\end{aligned}
$$

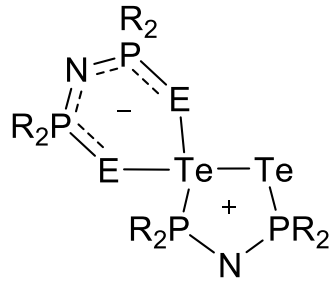

$$
\begin{aligned}
& \text { 5a' }(\mathrm{E}=\mathrm{Te}) \\
& \text { 5b' }(E=S e) \\
& 5 c^{\prime}(E=S)
\end{aligned}
$$




\section{Chart 2}

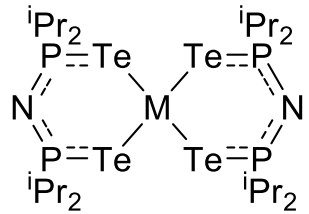

$8 \mathbf{a}(\mathrm{M}=\mathrm{Ni})$

$8 b(M=P d)$

$8 c(M=P t)$

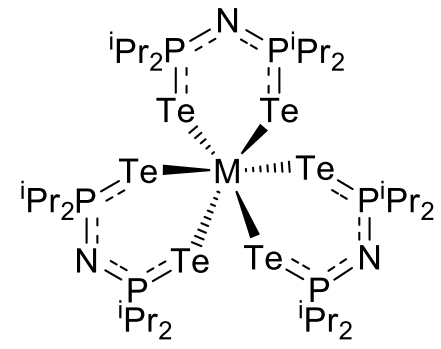

$10 a(M=S b) \quad 10 c(M=L a)$

$10 \mathrm{~b}(\mathrm{M}=\mathrm{Bi}) \quad 10 \mathrm{~d}(\mathrm{M}=\mathrm{U})$

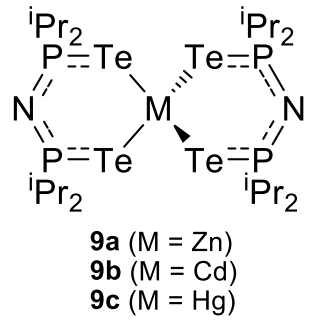

${ }^{\mathrm{i}} \mathrm{Pr}_{2} \mathrm{P}=\mathrm{N}$

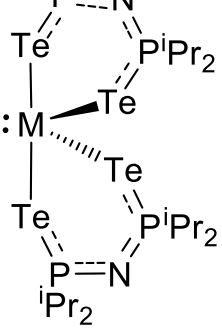

$11 \mathbf{a}(\mathrm{M}=\mathrm{Sn})$ $11 b(M=P b)$

\section{Chart 3}
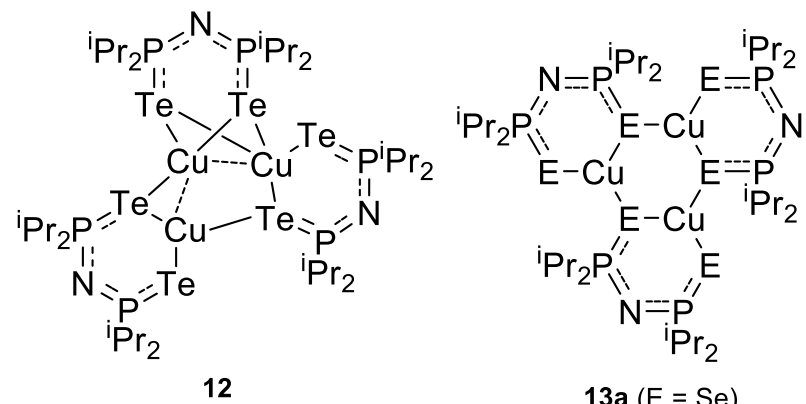

12

$13 a(E=S e)$

13b $(E=S)$

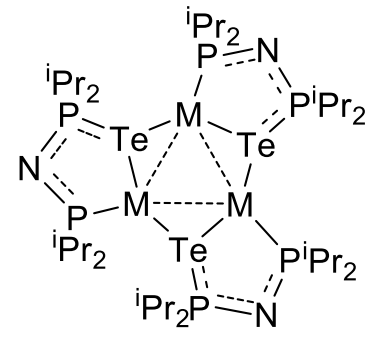

15a $(\mathrm{M}=\mathrm{Cu})$

15b $(M=A g)$ 


\section{Chart 4}

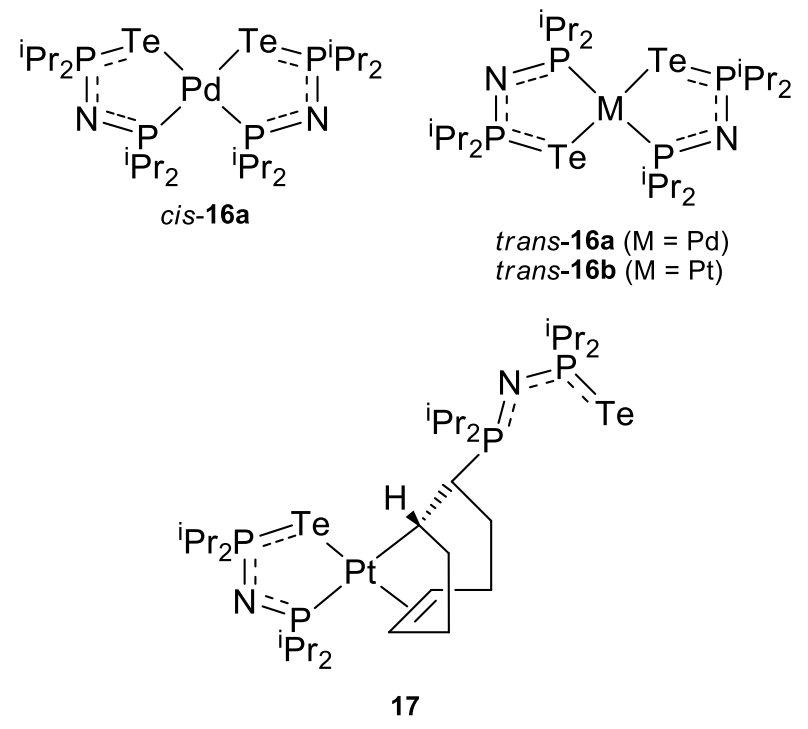

Figure 1

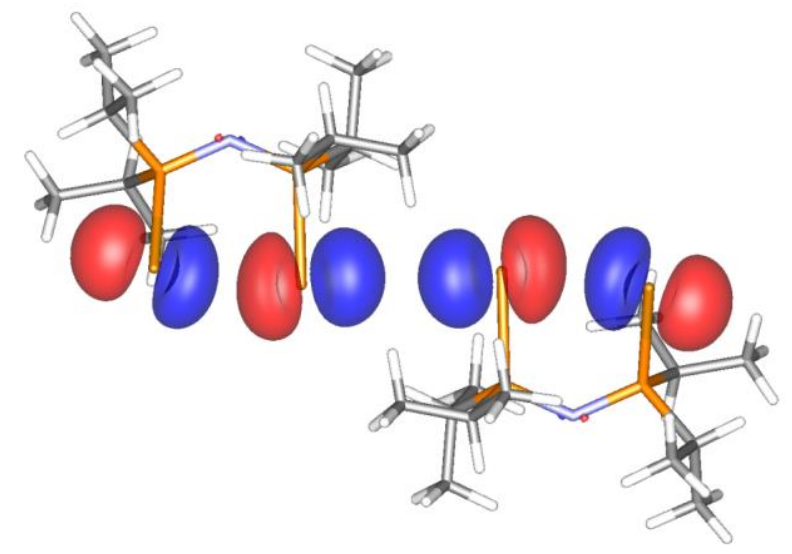

Figure 2

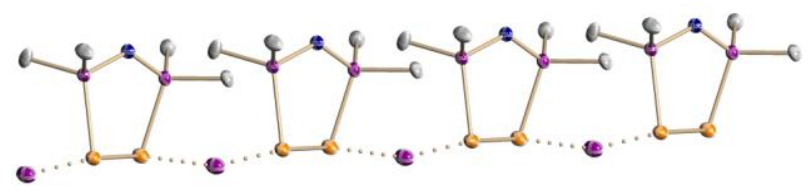


Figure 3

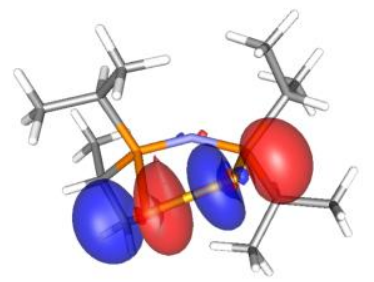

LUMO

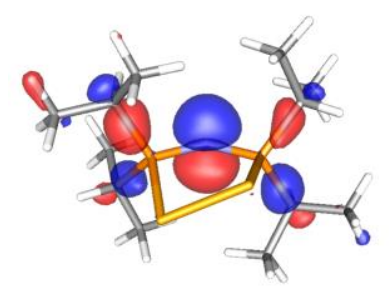

HOMO-1

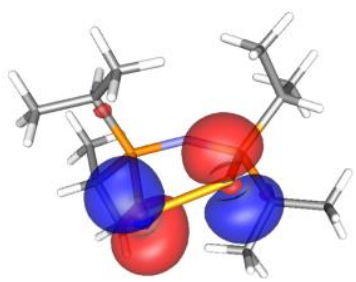

HOMO

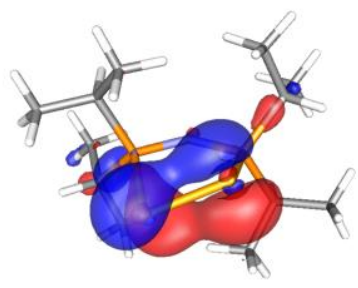

HOMO-2 


\section{Equations}

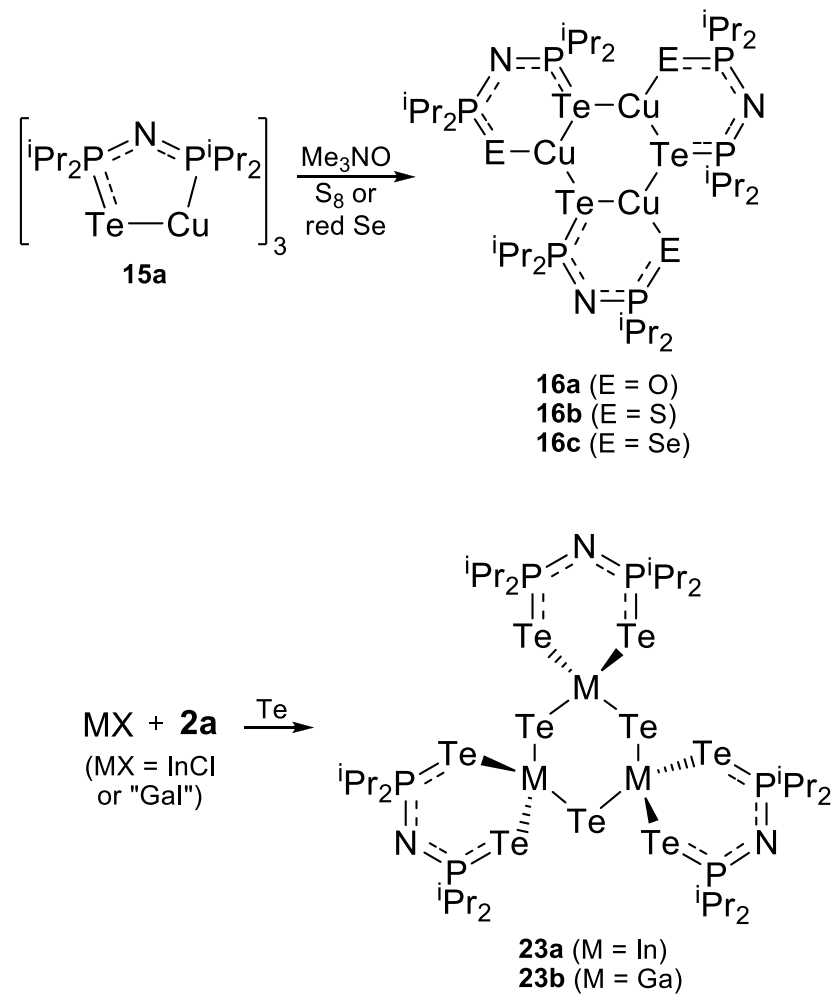

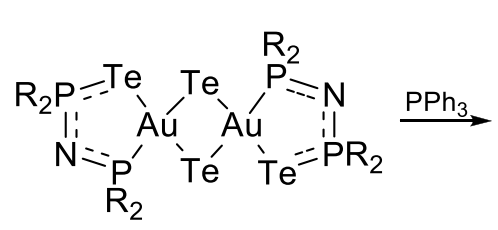

$25\left(\mathrm{R}=\mathrm{Ph},{ }^{\mathrm{i}} \mathrm{Pr},{ }^{\mathrm{t}} \mathrm{Bu}\right)$

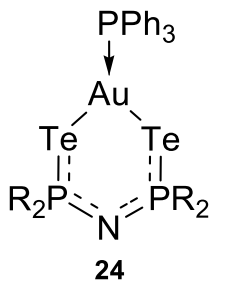

(3) 


\section{$\underline{\text { List of Figure and Scheme Captions }}$}

SCHEME 1. Synthesis of mono and dichalcogenido imidodiphosphinate ligands

SCHEME 2. Synthesis of cyclic cations $\left[\mathrm{N}\left(\mathrm{P}^{\mathrm{i}} \mathrm{Pr}_{2} \mathrm{E}\right)_{2}\right]^{+}(\mathrm{E}=\mathrm{Se}, \mathrm{Te})$

SCHEME 3. Formation of a $\mathrm{Ga}_{2} \mathrm{Te}_{2}$ ring via intramolecular oxidative addition

FIGURE 1. Bonding interaction between two [TePi $\left.\operatorname{Pr}_{2} \mathrm{~N}^{\mathrm{i}} \mathrm{Pr}_{2} \mathrm{PTe}\right]^{\bullet} \mathrm{SOMOs}$

FIGURE 2. Polymeric structure of $\left[\mathrm{N}\left(\mathrm{P}^{\mathrm{i}} \mathrm{Pr}_{2} \mathrm{E}\right)_{2}\right] \mathrm{I}(\mathrm{E}=\mathrm{Se}, \mathrm{Te})$. Methyl groups and hydrogen atoms are omitted for clarity.

FIGURE 3. Frontier MOs of the cations $\left[\mathrm{N}\left(\mathrm{P}^{\mathrm{i}} \mathrm{Pr}_{2} \mathrm{E}\right)_{2}\right]^{+}(\mathrm{E}=\mathrm{Se}, \mathrm{Te})$ 